\title{
Clinical and etiopathological aspects of muscle and joint sports injuries
}

${ }^{1}$ Dr. Eugen Nicoară County Hospital, Reghin

${ }^{2}$ University of Medicine and Pharmacy, Tîrgu Mureş

${ }^{3}$ University of Medicine and Pharmacy, Tîrgu Mureş, County Emergency Hospital, Tîrgu Mureş

${ }^{4}$ County Emergency Hospital, Tîrgu Mureş

${ }^{5}$ Department of Anatomy, Faculty of medicine, University "Ovidius" Constanta

\begin{abstract}
.
This descriptive study was conducted on a group of 92 patients during January 2012 - December 2012, treated at the Sports Rehabilitation Department of NOVA VITA Medical Center, Tîrgu Mures. We investigated the incidence of muscle and joint injuries by age group, gender, region of the injured muscle and joint, type of sport. Football is the main sport practiced at a professional level, thus the leg is the most exposed body part to diseases at different levels and degrees, especially the ankle, knee and thigh with muscle damage and ligament injuries. Playing tennis at an amateur level can harm body parts like the shoulder and the elbow and can cause tendon and muscle injuries. The most affected region is the knee. Knee injuries are present in almost all sports. Nearly $40 \%$ of the injuries are ligament injuries.
\end{abstract}

Keywords: anatomical regions, lesion, sport

\section{Brînzaniuc Klara}

University of Medicine and Pharmacy, Tîrgu Mureş klara_brinzaniuc@yahoo.com

\section{Introduction}

Regarding the variety of the practiced sports, level of competition and sports performances at amateur or professional level, sports has recently undergone an extraordinary evolution, consequently this has led to the increase in number of patients presenting some kind of pathology of sports injuries. The study of sports traumatology is important for sports managers and decision makers, medical equipment manufacturers, practitioners, and last but not least for the family.

\section{Material and method}

Data were collected and analyzed from patients' medical files.

Structural indicators, frequency and mean values were calculated.

The FISHER test was used to verify the correlations between various characteristics of the studied group. 


\section{Results}

During the surveyed period there were a total number of 92 patients included in the study who suffered from muscle, tendon and ligament injuries after practicing a sport at an amateur or professional level. The gender distribution in the studied group is: 26 women (28\%) and 66 men (72\%) (Figure 1).

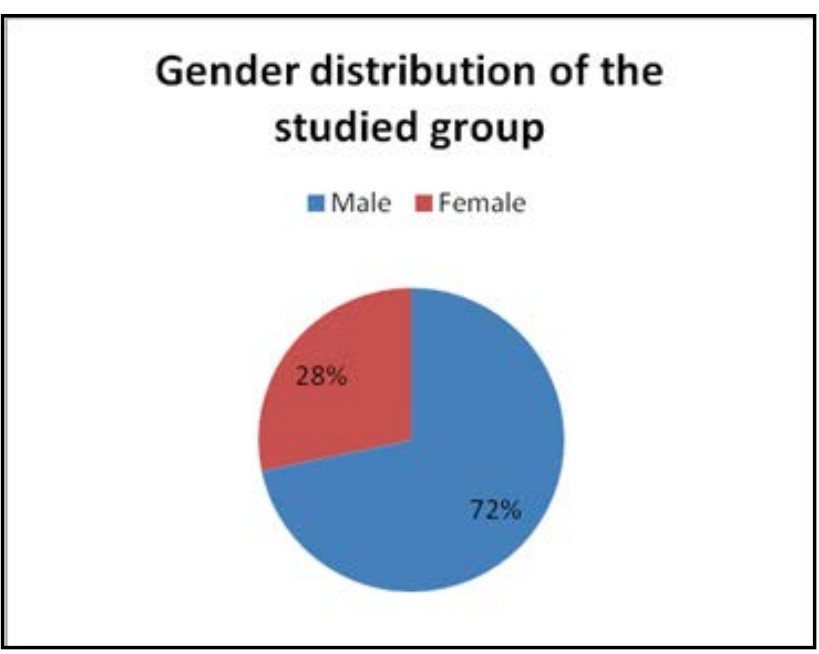

Figure 1

The mean age of the group was 33.5 years with a minimum of 15 and a maximum of 59 years old. Structures according to the age groups reveal that $11.96 \%$ were younger than 19 years old, $25 \%$ were between $20-29,33.7 \%$ between $30-39,23.91 \%$ between $40-49$ and $5.43 \%$ over 50 years old. Except for the age group of 40-49 years old where gender distribution is equal. In the rest of the age groups males are better represented in a proportion of values ranging between 2.4 and 6.6 (Figures 2 and 3).

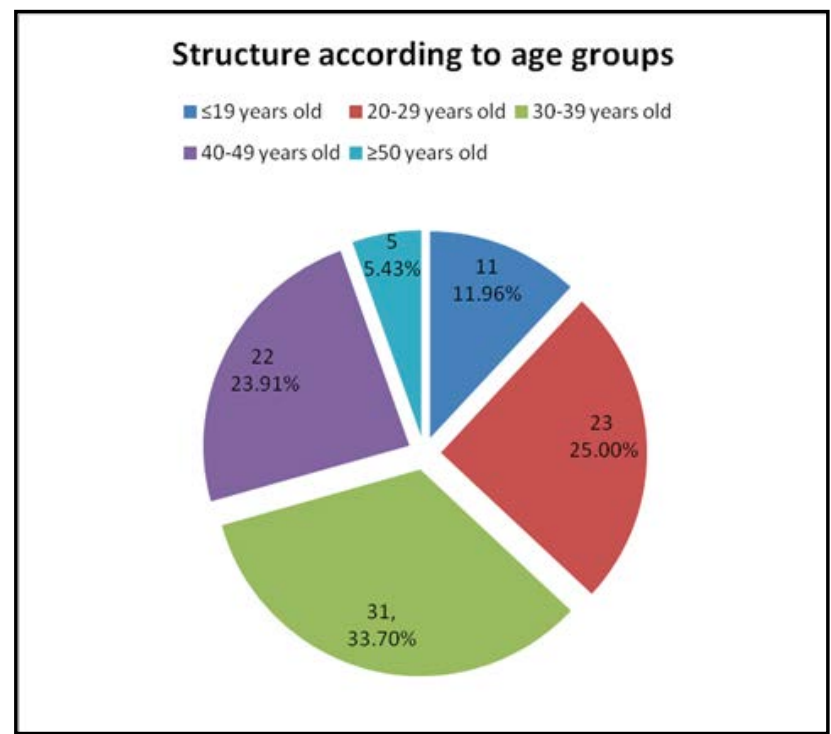

Figure 2

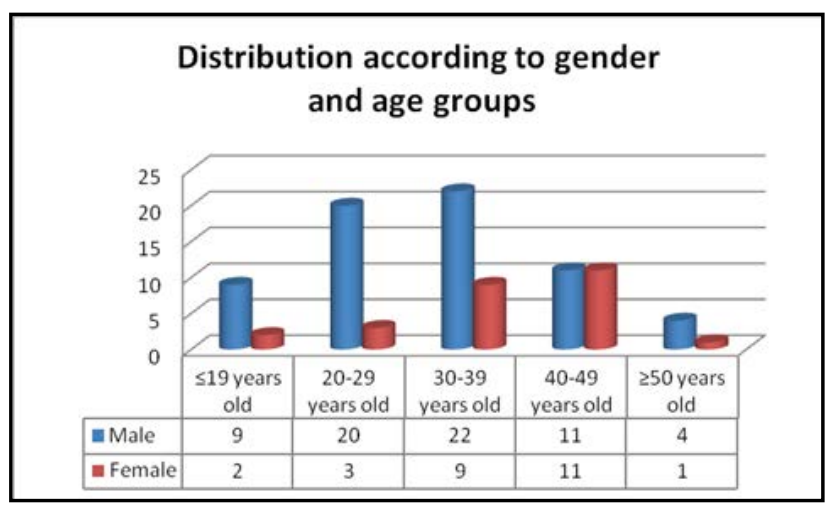

Figure 3

The analysis according to the way of doing a sport and type of practiced sport shows that $60 \%$ are amateurs and $40 \%$ are professionals of those who perform individual or group sports, moreover dominated by group sports like football, basketball, handball, tennis followed by individual sports like skiing. At the professional level sports like football, basketball and handball, and at the amateur level tennis, football and skiing are the most common ones. The category of "non-athletes" includes those who have suffered domestic, accidental injuries, not related to the performance of a sport, and the category of "other sports" comprises sportsmen who practice aerobics, fitness, judo, table tennis, bowling and hockey (Figures 4 and 5). 


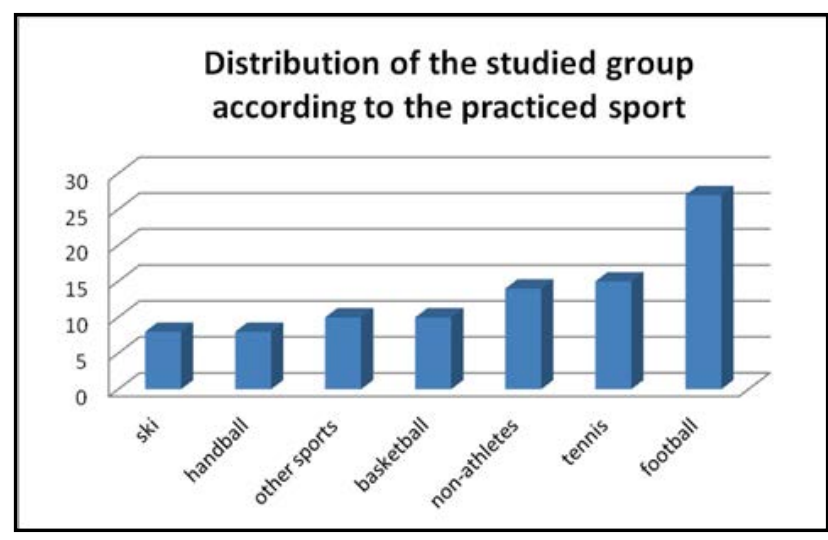

Figure 4

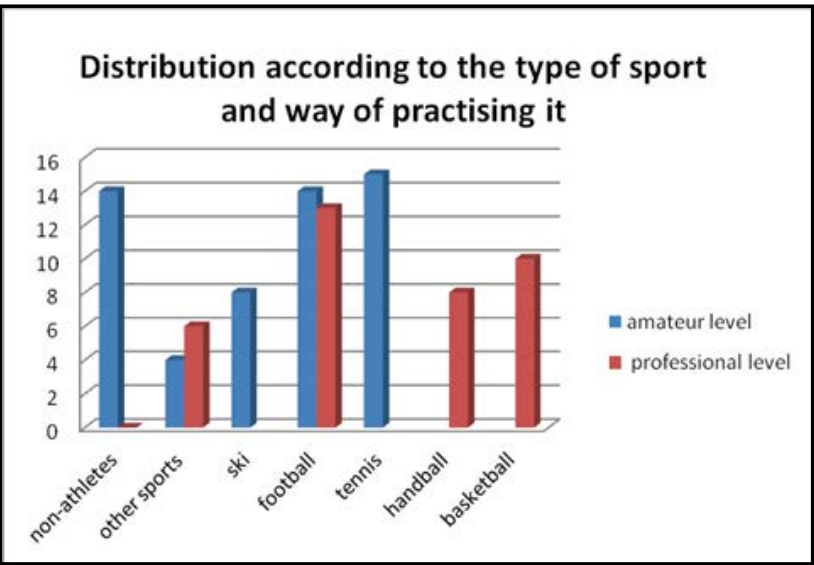

Figure 5

The affected areas after practicing a sport indicate that the most affected region is the knee, in one third of the cases, followed by the ankle, shoulder and thigh. Other areas include a small number of cases and involve the forearm, pectoral, pelvic, wrist, elbow and leg regions (Figure 6). Distribution by the affected region and practiced sport is shown in Table
I.

Distribution according to the affected regions

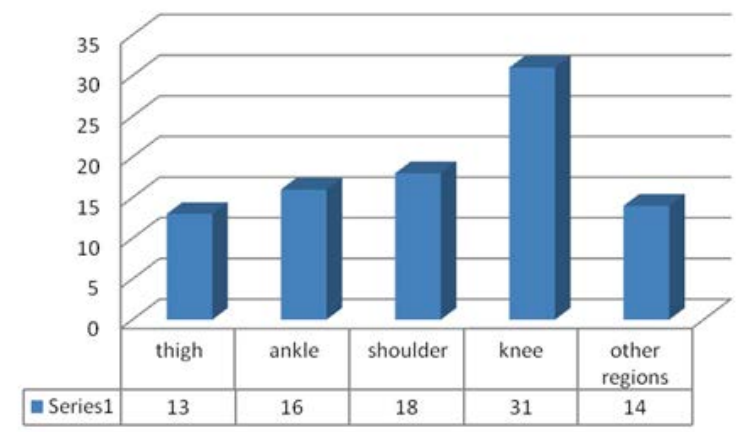

Figure 6

Our study shows that at the level of lesion, including muscles, tendon and ligament injuries, the most affected structures are the ligaments in 39\%, followed by tendon and muscle. We noticed that $11 \%$ of the cases were combined injuries of the above mentioned areas (Figure 7).

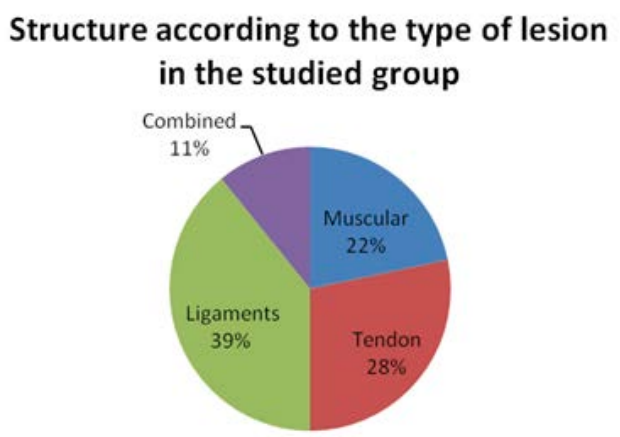

Figure 7

There are specific injuries according to the

Table I

\begin{tabular}{|l|c|c|c|c|c|c|c|c|}
\hline Region & Other sports & Handball & Tennis & Football & Ski & Basketball & Non athletes & TOTAL \\
\hline Thigh & & 3 & & 7 & & 2 & 1 & 13 \\
\hline Ankle & & 1 & 1 & 9 & 2 & 2 & 1 & 16 \\
\hline Shoulder & 1 & 1 & 5 & 2 & & & 9 & 18 \\
\hline Knee & 6 & 3 & 3 & 8 & 6 & 2 & 3 & 31 \\
\hline Other regions & 3 & & 6 & 1 & & 4 & & 14 \\
\hline TOTAL & 10 & 8 & 15 & 27 & 8 & 10 & 14 & 92 \\
\hline
\end{tabular}


practiced sport. In case of football ligament and muscle injuries, in case of ski ligament injuries, in case of tennis tendon injuries are the most common traumas. Combined lesions occur more frequently in those who have previously undergone domestic trauma (Figure 8).

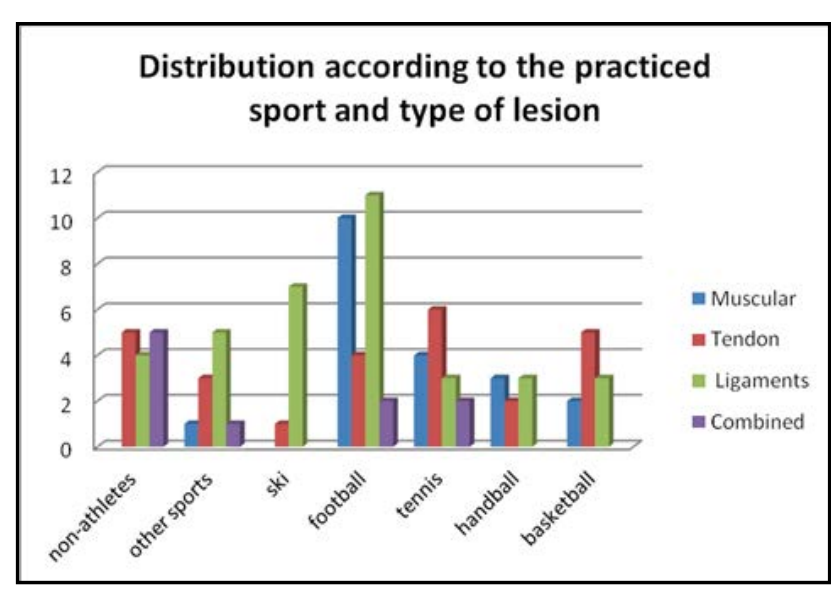

Figure 8

Over $80 \%$ of ligament injuries occur at the level of the knee. Muscle injuries are related to the thigh region in $55 \%$ of the cases and tendon injuries occur most frequently in the ankle and shoulder regions (Figure 9).

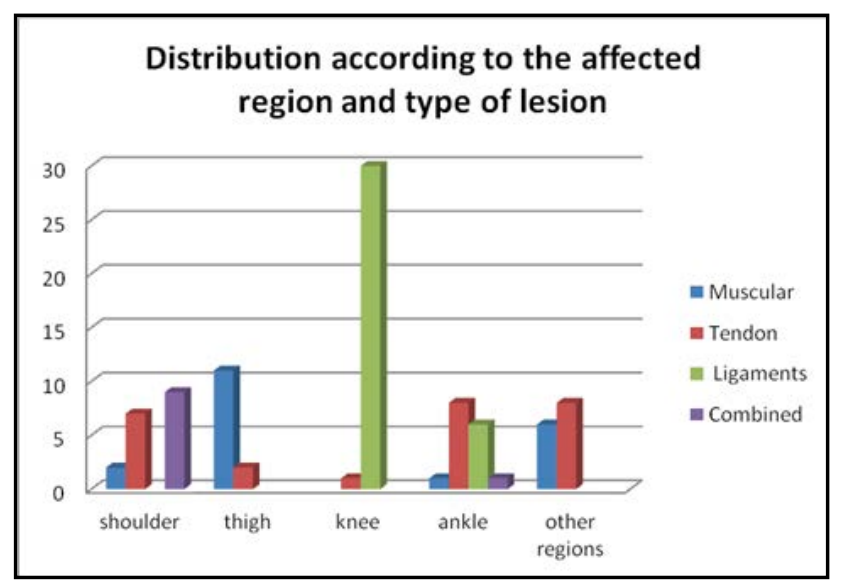

Figure 9
Discussions

The analysis of the link between the practiced sport and affected areas showed that the trauma of the knee area is related to the practice of football and ski $(\mathrm{p}<0.05)$, the ankle region to football $(\mathrm{p}<0.05)$, the shoulder area to tennis and trauma in non-athletes ( $p$ $<0.05$ ) and thigh region to football.

Surveys show that there is a link between the practiced sport and type of injury, thus between football and muscle injuries, ski and ligament injuries $(\mathrm{p}<0.05)$, tennis and tendon lesions $(\mathrm{p}<0.05)$.

Observing the association between the type of injury and affected region there are relevant relationships between ligament injuries and knee region, tendon injuries and ankle and shoulder region $(\mathrm{p}<0.05)$, muscle injuries and thigh region $(\mathrm{p}<0.05)$, and compound injuries of the shoulder joint $(\mathrm{p}<0.05)$.

\section{Conclusions}

The most common injuries occur in males $(72 \%)$ similar to data published in the specialty literature.

The most affected region by traumatisms is the knee, one third of the cases, knee injuries are present in all sports practiced by the individuals comprised in the study group.

At the level of traumatisms, the most affected areas are the ligament structures in 39\%, which occur due to skiing and playing football at an amateur level and due to football at the professional level. 
1. Poenaru, D.V. \& Matusz, P.L. (1994). Traumatologie sportivă. Timişoara: Ed. Mirton

2. Măruşteri, M. (2006). Noţiuni fundamentale de biostatistică. Note de curs. Tîrgu Mureş: Ed.Univ Press

3. Milner, Ed.M. The Epidemiology of sports injuries, or Caveat Emptor, International Association for Sports Surface Sciences, Retrieved from http://www.isss-sportsurfacescience.org/ downloads/documents/6EGQHIOVRC_Milner. pdf

4. Armsey, T.D. \& Hosey, R.G. (2004). Medical aspects of sports: epidemiology of injuries, preparticipation physical examination, and drugs in sport, Clin Sports Med. 23, 255 - 279 